\title{
INTRODUCTION
}

\author{
ALEXANDRA ANNA SPALEK \& MATTHEW GOTHAM \\ University of Oslo
}

[1] BACKGROUND TO THIS ISSUE: THE COPO 2017 WORKSHOP

Coercion is the term used for a variety of phenomena whereby the interpretation of an expression seems to vary depending on another expression that it stands in a predication or modification relationship with. Some examples of coercion that are prominently discussed in the literature are given in the following sentences and contrasts, along with possible interpretations.

(1) a. Fred began a book.

b. Fred began an essay.

began reading? began writing?

(2) a. Fred is a good boy. morally good?

b. Fred is a good pianist. good at playing?

(3) a. Fred froze the water.

b. Fred froze the bottle.

the contents of the bottle?

(4) a. Fred drinks coffee.

b. Fred drank two coffees. two cups of coffee?

(5) a. Fred played the sonata for $1 \mathrm{~min}$.

a complete sonata?

b. Fred played the piano for 10 years.

without pause?

Coercion is widespread and has often been remarked on within formal semantics, pragmatics and computational linguistics (Pustejovsky 1995; Egg 2003; de Swart 2011; Asher 2011; Dölling 2014; Piñango \& Deo 2016; Lukassek \& Spalek 2018; Nunberg 1979; Recanati 2004). However, the nature of coercion remains not well-understood in various respects and its theoretical account is still much discussed. Thus the workshop Approaches to Coercion and Polysemy (CoPo 2017), held at the University of Oslo on 20-21 November 2017, was organized so as to particularly focus on the following questions:

- To what extent do examples like (1)-(5) represent a unified phenomenon, and what constrains the availability of these kinds of enriched interpretations?

- What do these examples tell us about the nature of the lexicon, and the nature of predication? 
- To what extent do we need lexical meaning to be context-dependent?

- To what extent do we need a more sophisticated compositional system than is commonly assumed in formal semantics?

- How can the coerced interpretation be formally implemented?

It was our intention in organizing the workshop to create a forum to enable comparison of lexical, compositional and pragmatic approaches to these questions, and interaction between people coming from formal semantics, pragmatics and computational linguistics backgrounds. We were particularly interested in the interaction between coercion and the wider issue of polysemy, where a word may have more than one closely-related meaning.

In the event, we had contributions looking at coercion and polysemy from the perspectives, and using the techniques, of psycholinguistics, corpus linguistics, syntax, distributional semantics and logical semantics. We had semantic analyses couched in simple type theory (Church 1940) but also in various extended type theories: Generative Lexicon (Pustejovsky 1995), Type Theory with Records (Cooper 2005), Type Composition Logic (Asher 2011), and variations on MartinLöf's intuitionistic type theory (Martin-Löf 1975, 1984). The programme of the workshop was as follows:

(i) Katherine Fraser: Polysemy of an English Posture Verb: A Case Study of NonLiteral Meaning

(ii) Patrick Murphy: 'I'm done my homework': Complement Coercion and Aspectual Adjectives in Canadian English

(iii) Jan Wiślicki: Dispensing with Unwanted Polysemy: Deriving Verbal Idioms by Coercive Typing

(iv) Nicholas Asher: Type Presuppositions and Fine Grained Types: From Coercion to Co-composition and a Finer Grained Look at Determiners

(v) Julia Lukassek: Coercion and Underspecification Integrated: The State-EventAmbiguity of Aspectual Verbs

(vi) Markus Egg: Semelfactives

(vii) Bryan Leferman: The Aspectual Uniformity of Evaluative Adjectives

(viii) Emmanuele Chersoni, Alessandro Lenci \& Philippe Blache: Modeling the Compositional Cost of Logical Metonymies with Distributional Semantics

(ix) Robin Cooper: Coercion in Languages in Flux 
(x) Peter Sutton \& Hana Filip: Coercion: Container, Contents and Measure Readings

(xi) Stergios Chatzikyriakidis \& Zhaohui Luo: Identity Criteria of CNs: Quantification and Copredication

(xii) Eriko Kinoshita, Koji Mineshima \& Daisuke Bekki: Coercion as Proof Search in Dependent Type Semantics

(xiii) Alexandra Anna Spalek \& Matthew Gotham: Closing Comments and Discussion

Abstracts of the talks are available online at www . tinyurl.com/CoPo2017/.

[2] This special issue of oslo studies in language (osla)

This special issue of OSLa contains eight of the contributions from the CoPo 2017 workshop. The first four articles in this volume present diverse rich empirical data, both documenting novel contexts where we find coercion (see Fraser and Murphy) and providing new theoretical accounts of well-known phenomena (see Wiślicki and Egg).

The article that opens the volume provides a rich description of English posture verbs with a special focus on sit. Based on an in-depth exploration of English corpus data, Katherine Fraser illustrates that posture verbs are regularly ambiguous between their literal and non-literal readings, but that sit stands out in that its non-literal meaning does not merely encode a posture orientation in a metaphorical extension. Rather, it is regularly ambiguous between its primary meaning that describes a sitting posture and its secondary meaning that denotes an idle state, frequently with a negative connotation. In its secondary reading, sit puts no constraints on the position, but requires a location argument and restricts the state to be transitory, expressed either by means of progressive aspect or a secondary predicate. Fraser's case study of English posture verbs thus points to the need for coercion as a regular reinterpretation mechanism.

The second article reports on an eye-tracking experiment that examines an English dialectal construction, where coercion is at play. After testing processing times for the Canadian English I'm done/finished + noun phrase, Patrick Murphy reports increased processing times for the construction, when the noun phrase denotes an entity (e.g. comic), but not when it denotes an event (e.g. audition). These experimental results are reminiscent of what is known about aspectual verbs like finish, which trigger complement coercion with entity denoting nouns. Murphy interprets the additional processing cost of I'm done/finished the comic in line with a previous proposal by Fruehwald \& Myler (2015), who argued that done and finished are adjectival versions of aspectual verbs that semantically select for event descriptions and trigger complement coercion in case of entity-denoting nouns. This psycholinguistic paper thus reports clear coercion effects for the Canadian 
English construction in support of Fruehwald \& Myler (2015), and although it favors a type-shifting account, it leaves room for further theoretical discussion about the exact nature of the underlying semantic adjustments.

The third article in the collection, by Jan Wiślicki, turns to idioms as a potential empirical challenge, likely to represent a disruption in the compositional system. It points out that, traditionally, idioms have been understood as noncompositional units that are stored in the lexicon as variants of polysemous lexical items. In opposition to this view, the author develops a novel way of analysing idioms, which fits with general linguistic processes. Based on a couple of well-known examples, Wiślicki shows that idioms can be understood as emerging from cyclic derivation and a kind of structural coercion, where syntactic derivation marks the proper points for lexicalization of the strictly idiomatic parts. Coercion in this paper is thus redefined in a novel way as a pre-semantic operation that occurs at the derivation level and serves in storing complex conceptual information that can become a lexicalized item. Combining these two mechanisms allows Wiślicki to give an explanation for the puzzling property of idioms which exhibit atomic behaviour alongside varying degrees of morphosyntactic accessibility and flexibility.

The fourth article, by Markus Egg, discusses the class of semelfactive verbs and their variable aspectual properties in English and contrasts them with Russian and Hungarian, which use richer verb morphology to indicate aspectual differences. After reviewing previous analyses of semelfactives, the author defends an account that treats semelfactives as denoting singleton eventualities, whereas the iterative use of semelfactives in English is derived as a result of aspectual coercion. In line with his previous works on other meaning adjustment phenomena (Egg 2003, for example), Egg models coercion in terms of a suitable operator (here: an iterative coercion operator), which avoids an impending aspectual mismatch for semelfactives that are the complement of durative verbs such as keep on or are modified by durative adverbials. By postulating a coercion operator for the iterative readings of semelfactives the author turns to a well-known semantic resource that helps to avoid compositional conflicts and dispenses with unnecessary polysemy.

The final four articles in this volume explore various linguistic phenomena involving coercion and polysemy using extended type theories which, to a greater or lesser degree, make meaning adjustments something to be expected. The fifth article, by Robin Cooper, is a programmatic paper in which he outlines and motivates a view of linguistic semantics according to which it is a somewhat chaotic system subject to communicative constraints. On this view, coercion does not represent a disturbance in a highly formal and precise linguistic system, but rather a regularization of a highly flexible one. Cooper illustrates this perspective on language by means of two case studies, which he analyzes using Type Theory with Records 
(TTR). The first is the phenomenon of what Krifka (1990) called 'event-related readings'; for example, the interpretation of four thousand ships passed through the lock involving quantification not over ships, but over lock traversals. The second is the development of dynamic generalized quantifier theory, which is argued to be an example of where property coercions are part of the basic compositional semantic system, rather than something used only to generate additional interpretations for expressions.

In the sixth article, Peter R. Sutton and Hana Filip provide an analysis in TTR of the various coercion interpretations that are available when a numerical quantifier combines with a mass noun, as in e.g. two beers. They note that the container interpretation ('two glasses filled with beer') and the portion interpretation ('two portions of beer, each equivalent to the contents of one glass') are easier to arrive at than the measure interpretation ('beer to the amount of two glassfuls')-which is some ways is surprising, since this discrepancy is not evident for the equivalent full pseudo-partitive two glasses of beer. They argue that the explanation is that the measure interpretation is derived by an additional coercion from the portion interpretation which, along with the container interpretation, is lexically encoded in a dot-type in the sense of Pustejovsky (1995). They motivate this analysis with data from copredication.

The seventh article also deals with copredication data. Building on previous work that interprets common nouns as types and addresses copredication by means of dot-types in a subtype hierarchy, e.g. in which воок is a subtype of PHYS $\bullet$ INFO which is a subtype of PHYS, Stergios Chatzikyriakidis and Zhaohui Luo expand their analysis to account for entailment data in copredication sentences that rely on e.g. books-as-physical-objects having different individuation criteria to books-as-informational-objects. The crucial element is to interpret common nouns as setoids, i.e. pairs consisting of a type and an equivalence relation. This then opens up the possibility that these equivalence relations are not necessarily preserved when moving from a type to any of its supertypes, which turns out to be exactly what is required to account for the entailment data in copredication.

In the eighth and final article, Eriko Kinoshita, Koji Mineshima and Daisuke Bekki give an account of coercion behaviour that isn't triggered by a type mismatch; an example would be an interpretation of the lion escaped in which the lion is interpreted as referring to an actor playing the part of a lion. Building on previous work in Dependent Type Semantics (DTS) that treats selectional restrictions as presuppositions, and presupposition satisfaction as resolved by type checking, they present an account according to which each predicate encodes a 'transfer frame', which expresses the presupposition that there is a contextually salient relation between the argument to the predicate and something satisfying the selectional restrictions of the predicate (where identity is always contextuallly salient). 


\section{[3] REFLECTIONS}

The contributions to the CoPo 2017 workshop, and this volume, show natural language to be a highly flexible and adaptable system. Whether or not we take this flexibility and adaptability to be evidence, as Cooper puts it in this volume, that 'speakers of a natural language are constantly in the process of creating new language to meet the needs of novel situations in which they find themselves', they indicate that meaning adjustments described as coercion and polysemy are too widespread and multifaceted to be viewed simply as the exception that proves the rule. This is the reason why more and more research in formal semantics, pragmatics and computational linguistics is making an effort to meet the needs of natural language and incorporate adjustment mechanisms, such as coercion, as a part of their regular inventory of tools.

What the diversity of empirical data and theoretical approaches united in this volume however also illustrate, is that enriched interpretations and the nature of coercion are still a very rich area of ongoing research, on which diverse researchers differ in the way they understand, constrain and formalise coercion.

\section{AC KNOWLEDGMENTS}

The CoPo 2017 workshop was funded jointly by the Department of Literature, Area Studies and European Languages, and the Department of Philosophy, Classics, History of Art and Ideas, at the University of Oslo. It would not have been possible without the help of our session chairs and others who helped with practicalities: Elena Callegari, Atle Grønn, Nick Allott, Pritty Patel-Grosz, Kjell Johan Sæbø, Dag Haug and Cathrine Fabricius Hansen. We are also greatly indebted to our reviewers for both the workshop and this volume. The intellectual energy behind the workshop came from interactions in the SynSem research programme in the Faculty of Humanities at the University of Oslo, which we will remember very fondly.

\section{REF EREN C ES}

Asher, Nicholas. 2011. Lexical meaning in context. Cambridge: Cambridge University Press.

Church, Alonzo. 1940. A formulation of the simple theory of types. The Journal of Symbolic Logic 5(2). 56-68.

Cooper, Robin. 2005. Records and record types in semantic theory. Journal of Logic and Computation 15(2). 99-112.

Dölling, Johannes. 2014. Aspectual coercion and eventuality structure. In Klaus Robering (ed.), Events, arguments, and aspects: Topics in the semantics of verbs, 189226. Amsterdam: John Benjamins. 
Egg, Markus. 2003. Beginning novels and finishing hamburgers: Remarks on the semantics of to begin. Journal of Semantics 20(2). 163-191. doi:10.1093/jos/20.2. 163.

Fruehwald, Josef \& Neil Myler. 2015. I'm done my homework - case assignment in a stative passive. Linguistic Variation 15(2). 141-168.

Krifka, Manfred. 1990. Four thousand ships passed through the lock. Linguistics and Philosophy 13. 487-520.

Lukassek, Julia \& Alexandra Anna Spalek. 2018. Distinguishing coercion and underspecification in Type Composition Logic. In Uli Sauerland \& Stephanie Solt (eds.), Proceedings of Sinn und Bedeutung 22, 71-87. ZAS.

Martin-Löf, Per. 1975. An intuitionistic theory of types: Predicative part. In H.E. Rose \& J.C. Shepherdson (eds.), Logic colloquium '73 (Studies in Logic and the Foundations of Mathematics 80), 73-118. Amsterdam: North-Holland.

Martin-Löf, Per. 1984. Intuitionistic type theory. Naples: Bibliopolis.

Nunberg, Geoffrey. 1979. The non-uniqueness of semantic solutions: Polysemy. Linguistics and Philosophy 3(2). 143-184. doi:10.1007/BF00126509.

Piñango, Maria Mercedes \& Ashwini Deo. 2016. Reanalyzing the complement coercion effect through a generalized lexical semantics for aspectual verbs. Journal of Semantics 33(2). 359-408.

Pustejovsky, James. 1995. The generative lexicon. Cambridge, MA: MIT Press.

Recanati, François. 2004. Literal meaning. Cambridge: Cambridge University Press.

de Swart, Henriëtte. 2011. Mismatches and coercion. In Claudia Maienborn, Paul Portner \& Klaus von Heusinger (eds.), Semantics: An international handbook of natural language meaning, 574-597. Berlin: de Gruyter.

AUTHOR CONTACT INFORMATION

Alexandra Anna Spalek

University of Oslo

alexandraspalek@gmail.com

Matthew Gotham

University of Oslo

matthew.gotham@outlook.com 